\title{
REFERENCIAS A PEDRO ALFONSO DE HUESCA EN LA LITERATURA CASTELLANA DE LA EDAD MEDIA
}

\author{
María Jesús Lacarra \\ Universidad de Zaragoza
}

\begin{abstract}
RESUMEN
Las referencias que se hacen a Pedro Alfonso de Huesca en la literatura castellana de la Edad Media reflejan un conocimiento indirecto, derivado de la difusión de las obras de grandes escritores franceses e italianos, como Vicente de Beauvais, Guido de Colonna o Brunetto Latini. Solo los autores de otros textos apologéticos, muchas veces también conversos, parecen citarlo tras una lectura directa.
\end{abstract}

Palabras clave: Pedro Alfonso, literatura castellana medieval, recepción.

\begin{abstract}
The references made to Pedro Alfonso de Huesca in medieval Castilian literature show an indirect knowledge, derived from the diffusion of the works of major French and Italian authors, such as Vicente de Beauvais, Guido de Colonna or Brunetto Latini. Only the authors of other apologetic texts, often themselves converts, seem to mention him through direct reading.
\end{abstract}

Key words: Pedro Alfonso, medieval Castilian literature, reception.

La figura de Pedro Alfonso (ca.1065-1121), judío converso y habitante de Huesca en los primeros años del siglo XII, ejemplifica perfectamente la unión entre la cultura andalusí y los nacientes reinos cristianos. Su producción conservada incluye una obra apologética, los Dialogi contra Iudaeos, un tratado didáctico, la Disciplina clericalis, la versión de los Zij («tablas») de al-Khwarizmi, y una Epistola ad peripateticos. Especialmente las dos primeras obras citadas gozaron de una popularidad inmensa en los círculos cultos de la Europa occidental, favorecida sin duda por estar escritas en latín. La Disciplina clericalis, miscelánea de cuentos y sentencias, permitió el trasvase hasta Occidente de diversas formas didácticas procedentes de la cultura oriental, mientras que los Dialogi se convirtieron en el texto apologético más importante de la Edad Media. Si añadimos su obra científica, mal conservada, podemos concluir que se trata de uno de los conversos que más aportaron a la historia cultural de Occidente, como lo muestran los numerosos manuscritos de sus obras repartidos por toda Europa. De la Disciplina clericalis han llegado hasta nosotros 76, pero sólo cuatro testimonios peninsulares (Barcelona, Córdoba, El Escorial y Tarragona); de los Dialogi contamos con 79 manuscritos (sumando reelaboraciones y extractos), cinco de ellos en la Península (Burgo de Osma, Salamanca, Santo Domingo de la Calzada, Tarragona y Tortosa), más dos fragmentos en Barcelona de una traducción catalana, posiblemente como la custodiada por Benedicto XIII en su biblioteca de Peñíscola ${ }^{1}$. Ninguna de estas

1 John Tolan, en su interesante estudio Petrus Alfonsi and His Medieval Readers, Gainesville, University 
obras alcanzó, directamente, la difusión impresa en España, aunque el manuscrito salmantino, del siglo XVI, estaba preparado ya para ello.

Podemos, pues, preguntarnos qué conocimiento tenían los autores hispanos de la obra de Pedro Alfonso y de su figura. Restringiendo la búsqueda al campo de los textos en castellano, encontramos el nombre de Pedro Alfonso (Per Alfonso, Peralfons o Alfonso, simplemente) en diversas obras, tanto en prosa como en verso. En la mayoría de las ocasiones las referencias no indican ni mucho menos una lectura directa de la producción del converso. Las falsas atribuciones a nuestro autor, así como las confusiones en los mínimos datos biográficos que se recogen, denotan muchas veces que se trata de citas de segunda mano. Un recorrido por alguno de estos pasajes nos permitirá ir descubriendo en muchos casos el origen de las informaciones.

Ya señalábamos en otra ocasión que la Disciplina clericalis no tuvo en su lugar de origen la popularidad que alcanzó en otros muchos puntos del Occidente cristiano ${ }^{2}$. La reiteración en los ejemplarios de historias procedentes de la Disciplina raras veces permite pensar en un conocimiento directo. Muchas veces llegan los relatos desprovistos de cualquier indicación que ayude a localizar su fuente última o con una atribución a una autoridad imprecisa (Dijo el sabio, cuenta un árabe, etc.). En el Libro de los exemplos por abc, la obra castellana que incluye más ejemplos procedentes de la Disciplina clericalis, sólo en dos ocasiones se cita el nombre de su autor. En el inicio del n. ${ }^{\circ} 124$, versión del exemplum 22, «Dixo Petrus Alfonsus a su fijo», se identifica al personaje del sabio que dialoga con su hijo con el autor mismo. Sólo el n. ${ }^{\circ} 390$, versión del exemplum 16, menciona adecuadamente al comienzo al autor, sin precisar el título de la obra: «Cuenta Petrus Alfonsus en su tratado..».. Se trata en este caso de una versión abreviada de la historia, casi sin dramatizar, lo que denuncia a las claras la existencia de un texto intermedio. Este ejemplo de los «Diez toneles de aceite» tuvo una amplia difusión a través de otro tipo de tratados didácticos, como los espejos de príncipes, en los que se integró para ilustrar los pasajes dedicados al ejercicio de la justicia. En este nuevo contexto era conveniente vincular la narración a una «autoridad», con lo que se convertía en un caso jurídico ejemplar. Así lo encontramos en una fiel versión («desto cuenta Per Alfonso en el su tratado...») en la glosa de Juan García de Castrojeriz al Regimiento de príncipes de Egidio Romano.

Por el contrario, en el Espéculo de los legos, versión castellana de un ejemplario latino de finales del XIII, todos los ejemplos procedentes en última instancia de la Disciplina van asociados al nombre de su autor: «Recuenta Per Alfonso» (ex. 49), «E semejable enxienplo de aqueste fallarás en el libro de Per Alfonso» (ex. 489), etc. A la popularidad del nombre del converso, no exenta de confusiones, contribuirían también otros textos, con amplia difusión peninsular manuscrita e impresa, como el Ludus scaccorum, escrito por el dominico Jacobo de Cessoles a finales del siglo XIII. En el capítulo tercero de la versión castellana impresa se recogen los dos primeros ejemplos de la Disciplina, precedidos de esta indicación: «Refiere Petrus Alfonsus (que fue un philósopho d'Aravia) que tenía un solo fijo...» ${ }^{3}$. De este modo se identifica el autor (Pedro Alfonso), con el filósofo, que enmarca a veces las narraciones, y con el personaje del árabe a punto de morir que alecciona a su hijo en el ejemplo primero. Indu-

Press of Florida, 1993, recoge en apéndice una relación exhaustiva de testimonios manuscritos; en la segunda parte de este libro aporta numerosos datos para rastrear la huella de las obras de Pedro Alfonso en la cultura occidental. Véase también Estudios sobre Pedro Alfonso de Huesca, coord. M. ${ }^{a}$ Jesús Lacarra, Huesca, Instituto de Estudios Altoaragoneses, 1996, donde el lector interesado podrá encontrar una completa bibliografía.

2 M. Jesús Lacarra, «Ecos de la Disciplina clericalis en la tradición hispánica medieval», en Estudios sobre Pedro Alfonso de Huesca, ob. cit., pp. 275-289. Remito al lector a este artículo, donde se incluyen las referencias imprescindibles.

3 Dechado de la vida humana...moralmente sacado del Juego del Axedrez...por el Licenciado Reina, Valladolid, Francisco Femández de Córdoba, 1549 (facsímil Valencia, Castalia, 1952). Para las traducciones castellanas manuscritas de la obra de Cessoles, véase Alexandre Bataller Català, «Les traduccions castellanes del Liber de moribus de Jacobus de Cessulis», en Actas del VIII Congreso Internacional de la Asociación Hispánica de Literatura Medieval, Santander, 22-26 de septiembre de 1999, ed. M. Freixas y S. Iriso, Santander, AHLM, 2000, pp. $337-352$. 
dablemente estas confusiones contribuyen al exotismo del relato, al atribuir su origen a un filósofo de Arabia. Por último, conviene recordar que la mayoría de las versiones impresas del Esopo castellano incluyen en un último apartado, «Las fábulas colectas», varios relatos procedentes de la Disciplina. El epígrafe se limita a advertir: «Aquí comiençan las fábulas coletas de Alfonso...», lo que no serviría de mucho para sus innumerables lectores.

Las características de la obra, combinación de exempla y sentencias, hicieron que unos lectores prefirieran unos materiales antes que otros, como lo reflejan algunos manuscritos. Una decena copian sólo los exempla, pero otros sólo recogen las sentencias ${ }^{4}$. Pedro Alfonso pasa así a figurar no sólo en los ejemplarios sino a incluirse entre los auctores, cuyos proverbios se integran en florilegia, como los de Séneca, Salomón o Catón.

En algunas tratados didácticos en castellano encontramos a Pedro Alfonso citado como autoridad ${ }^{5}$. Así ocurre en el ms. 2882, conservado en la BNM y conocido como Cancionero de Juan Fernández de Hixar. Pese a que se trata de un conjunto poético, se insertan en él algunos textos en prosa, como un Tratado de retórica y la Flor de virtudes ${ }^{6}$. En el primero se recurre en tres ocasiones a la autoridad del converso:

Pedro Alfonso dize: Aquesto cela umana natura, que quando el cuerpo es movido por algún turbamiento, él pierde los ojos de la conosçençia entre verdad e mentira (p. 661; Dialogi, p. 9) ${ }^{7}$.

Pedro Alfonso dize: Por los amigos que tú no as asayado, te provee algunas vegadas de los enemigos, e mejor de los amigos (p. 665; $D C, 6.12$ ).

Pedro Alfonso dize: Non te aconpañes con tu enemigo, que si fazes mal, él te descubrirá; e si fazes bien, él telo asconderá; que, generalmente, deves guardar que parlas entre todas gentes, que munchos traen senblança de amigos, que son enemigos; qu'él mesmo dize: 'A todos aquellos que tú non conosçes, ayas sospecha que son tus enemigos; e si ellos quieren caminar contigo, e preguntan qué fazes, diles que non parles con honbre loco' (p. 665; DC, 6. 24).

En la Flor de virtudes encontramos sólo una mención a nuestro autor:

Pedro Alfonso dize: El irado non ha ojos (p. 702; Dialogi, p. 9).

La sorpresa inicial por el hallazgo de estas citas se aminora cuando averiguamos el origen de los textos. El anónimo Tratado de retórica se corresponde, como ha estudiado María Morrás, con la Doctrina de hablar e de callar hordenada por Marcho Tullio, obra directamente emparentada con el Tractatus de arte loquendi et tacendi de Albertano de Brescia (h.11921270). Por su parte, la Flor de virtudes es traducción de las Fiore di virtù, obra anónima escrita en la región de Bolonia en la primera mitad del siglo XIV ${ }^{8}$. Entre las diversas fuentes utilizadas por el autor de las Fiore está de nuevo Albertano.

4 Alfons Hilka y Werner Söderhjelm, eds., Disciplina clericalis I: Lateinischer Text, Acta Societatis Scientiarum Fennicae 38, n. ${ }^{\circ}$, Helsinki, 1911, menciona en p. xxvii los manuscritos que sólo incluyen exempla y en p. $\mathrm{XXIX}$ aquellos que sólo recogen los aforismos.

5 Excluyo de este estudio las obras en las que se recogen proverbios coincidentes con los de la Disciplina, pero sin citar directamente a Pedro Alfonso, cuyo origen puede estar en un trasfondo sapiencial común. Véase, por ejemplo, la obra de Sem Tob de Carrión, Proverbios morales, ed. Paloma Díaz-Mas y Carlos Mota, Madrid, Cátedra, 1998 (39c, 63a, 109a, 216b, 233b, 431a-b).

6 Cancionero de Juan Fernández de Ixar, ed. José M. a Azáceta, Madrid, CSIC (Clásicos Hispánicos), 1956, pp. 685-752.

7 Las correspondencias con la Disciplina se señalan por la citada edición de A. Hilka, con la indicación de página y línea. Para los Dialogi, sigo la edición de Klaus-Peter Mieth, con introducción de John Tolan y traducción de Esperanza Ducay, Huesca, Instituto de Estudios Altoaragoneses, 1996.

8 María Morrás, «Una compilación desconocida de traducciones y sentencias morales: el ms. 3190 de la Biblioteca de Cataluña», Incipit, XIII(1993), 87-104; M. Jesús Lacarra, «La Flor de virtudes y la tradición ejemplar», en Studia in honorem Germán Orduna, ed. L. Funes y J. L. Moure, Universidad de Alcalá, 2001, pp. 347-361. 
Conocemos muy pocas noticias acerca de este autor italiano, aparte de su condición de juez, aunque algunas de sus obras, como el De arte loquendi et tacendi (1245) y el Liber consolationis et consilii (1246), alcanzaron gran difusión, con traducciones y adaptaciones a distintas lenguas europeas ${ }^{9}$. Ambas están construidas a base de recurrir a 'autoridades' en el saber moral. Como señala G. E. Sansone ${ }^{10}$, Albertano es un buen representante de la cultura laica de la sociedad del Norte de Italia. De ahí que entre sus fuentes hayan desaparecido prácticamente los Padres de la Iglesia y en cambio combine citas bíblicas con autores clásicos y de la Edad Media latina. Es curioso observar, sin embargo, que en otros textos castellanos medievales, directamente emparentados con las obras de Albertano, se han borrado por completo muchas referencias a autoridades, como Pedro Alfonso, aunque en algún caso se conservan sus palabras, como ocurre en el Libro del consejo e de los consejeros ${ }^{11}$.

En el Libro del Tesoro, texto traducido al castellano a finales del siglo XIII, reencontramos citas muy similares:

Pedro Alfonso diz: Esto es en la natura humanal, que quando el entendimiento es comovido por algund torvamiento, pierde los ojos del conosçemiento que es entre verdat $\mathrm{e}$ falsedat (p. 131; Dialogi, p. 9) ${ }^{12}$.

Pero Alfonso diz: Toma miedo de dezir cosa por que te arrepientas, ca el sabio onbre deve callar por sí (p. 132; $D C, 8.9$ ).

Diz Pero Alfonso: Por los amigos que tú non avrás ensayados, proveete de los enemigos, el amigo non le ensayes tan solamente una vez más muchas, ca por aventura el amigo se tornará enemigo (p. 134; $D C$, 6.12).

Pero Alfonso diz: Non ayas conpañía con tus enemigos, ca si fazes mal, contarlo an, si fazes bien desfazerlo an. Generalmente entre todas gentes deves guardar lo que fablas, ca muchos ay que se muestran por amigos, e son enemigos (p. $134 ; D C, 6.24$ ).

Pero Alfonso diz: Todos aquellos que tú non conosçes, ave sospechas dello que son tus enemigos (p. 134; $D C, 6.24)$.

De nuevo estamos ante una traducción de una obra de un autor italiano, el florentino Brunetto Latini (h.1220-1293 ó 1294), quien hacia 1260 se encontraba en la corte de Alfonso X formando parte de una embajada. A su regreso a Italia conoció la derrota de los güelfos, lo que le llevó a exiliarse en Francia donde compuso, antes de 1269, el Libro del tesoro. Su estancia en la Península, dejando al margen las huellas que pudo dejar en su obra, quizá explique la gran popularidad del Tesoro en España, con más de quince manuscritos castellanos conservados, a los que hay que sumar las traducciones al catalán y al aragonés. Las referencias a Pedro Alfonso se agrupan todas en la segunda parte del libro, dedicada a la ética, en concreto entre los capítulos 50 al 132. Brunetto Latini se basó para este florilegio en otros autores, como el mismo Albertano de Brescia, de donde proceden sus sentencias del converso. Coinciden, tanto el Tratado de retórica como el Libro del Tesoro en incluir la misma cita procedente de los Dialogi;

9 Albertanus Brixiensis, Liber consolationis et consilii, ed. Thor Sundby, Copenhagen-London, N. Trübner \& Co. pro Societate Chauceriana, 1873; Albertano da Brescia, Liber de doctrina dicendi et tacendi. La parola del cittadino nell' Italia del Duecento, ed. Paola Navone, Firenze, Sismel-Edizione del Galluzzo, 1998. Véase ahora http://freespace.virgin.net/angus.graham, con bibliografía, edición de los textos y relación de versiones manuscritas vernáculas.

10 Albertano da Brescia, Llibre de consolació i de consell, ed. G. E. Sansone, Barcelona, Barcino, 1965, p. 13, n. 8 .

11 Maestre Pedro, Libro del consejo e de los consejeros, ed. Agapito Rey, Biblioteca del Hispanista-V, Zaragoza, Librería General, 1962; Juan Manuel Cacho Blecua, «Del Liber consolationis et consilii al Libro del cavallero Zifar», La Corónica, 27.3 (1999), 45-66, observa cómo en el texto del Zifar se han eliminado en su mayoría los nombres de las autoridades citadas por Albertano.

12 Libro del tesoro. Versión castellana de Li Livres dou tresor, ed. Spurgeon Baldwin, Madison, Hispanic Seminary of Medieval Studies, 1989. 
las restantes, transmitidas a veces con errores, derivan de la Disciplina, especialmente del apartado dedicado al consejo, muy popular por estar situado al inicio, tras los dos ejemplos de la amistad.

Las primeras noticias sobre la vida y la obra de Pedro Alfonso aparecen en textos castellanos del siglo XV, y derivan, directa o indirectamente, del Speculum historiale, compuesto por el dominico Vicente de Beauvais entre 1246-1253. Este libro es la segunda parte de una inmensa compilación, que alcanzó una gran difusión a lo largo de la Edad Media por su carácter enciclopédico. En el capítulo 118 del libro 25 incluye una breve semblanza de Pedro Alfonso, retomada de las palabras que el propio autor escribió en su prólogo a los Dialogi dando noticia de su conversión y bautismo. A continuación, y a lo largo de 28 capítulos, reproduce los cinco primeros títulos de Pedro Alfonso, incluido el quinto, dedicado a refutar los principios del islam. Sin embargo, como ha señalado John Tolan, Beauvais intenta readaptar, con algunos fallos, el diálogo a un monólogo y abrevia muchos pasajes ${ }^{13}$. Los más de doscientos manuscritos que han llegado hasta nosotros del Speculum historiale son un indicio de la popularidad de la obra. Muchos lectores conocerían a Pedro Alfonso a través de estos capítulos o a través de extractos realizados a su vez por otros cronistas o enciclopedistas. Este pudo ser el caso de Fernán Pérez de Guzmán y de Diego Rodríguez de Almela, pertenecientes ambos al círculo de humanistas que rodeaba al obispo de Burgos, y su vez converso, Alonso de Cartagena.

Fernán Pérez de Guzmán recoge en dos ocasiones una semblanza de Pedro Alfonso. La más extensa ocupa el capítulo 216 («Del dotor Per Alfonso de España el qual fue convertido a la fe») del Mar de historias:

Fue en este tienpo Per Alfonso que primero fue judío e llamado Moysés natural de Castilla. E dexó el judaísmo e convirtiose a la fe. E de su conversión escrivió un libro de asaz polido estilo, en el qual contra los judíos e moros disputó notablemente. En el comienço de su libro trató de la manera de la conversión suya diziendo así: «Dios todopoderoso me inspiró del su espíritu santo e me traxo a la verdadera carrera, tirándome de mis ojos las nubes que los cobrían. E entonçes me fueron abiertas las claustras de las profeçías e los secretos dellass me fueron revelados. E como por la misericordia de Dios viniese al exçelente grado de la santa fe, por instinto e graçia de la misericordia divina, luego me desnudé del manto desta falsedad e reçebí el bautismo en la iglesia de Osma en el nonbre del padre e del fijo e del espíritu santo por las manos del venerable don Estevan obispo de Osma, en el año del señor de .mcvj. años día de sant Pedro e sant Pablo. E por reverençia del glorioso apóstol sant Pedro tomé el nombre suyo, e porque fue mi padrino espiritual don Alfonso, glorioso enperador de España e me sacó de la sagrada fuente, tomé el nombre suyo por mi sobrenonbre e así só llamado Pedro Alfonso. E como los judíos que antes me conosçían e sabían ser yo letrado en los libros de la ley e de los profetas, sopiesen que avía reçebido la fe e ley de los christianos, cuidaron que yo lo avía fecho partiendo de mí toda vergüença, menospreçiara la ley de Dios; otros dezían que porque non entendía bien los dichos de los profetas; otros dezían que lo fiziera por vanagloria e porque veía que la gente de los christianos cada día cresçía e iva adelante» ${ }^{14}$.

El pasaje, como lo denuncia la confusión de Osma por Osca, es una traducción literal de Beauvais, pero a través de un texto intermedio, el Mare historiarum de Giovanni Colonna (1298-ca.1340/1343), como ha mostrado su reciente editor. El mismo Pérez de Guzmán vùel-

13 Vicente de Beauvais, Speculum historiale, vol. 4 del Speculum Maius, Duaci, 1624 (Graz, Akademischer Druck, 1964-1965). Para el estudio de esta sección es fundamental el trabajo de John Tolan, «The Speculum historiale Redaction of Petrus Alfonsi's Dialogi contra Iudaeos», Vicent of Beauvais Newsletter, 14(1989), pp. 4-10.

14 Fernán Pérez de Guzmán, Mar de historias, ed. A. Zinato, Padua, Biblioteca Spagnuola Unipress, 1999, pp. 262-263. 
ve a mencionar a Pedro Alfonso en sus Loores de los Claros Varones de Castilla y allí cita sus fuentes:

2753 A mi conviene que fable de Pero Alfonso, un doctor que contra el judaico error fizo un volumen notable; fue este varón loable de los ebreos nasçido y después que convertido, christiano muy venerable.

Al margen se añade una glosa: «Este doctor Pero Alfonso fue primero judío e gran sabio en aquella ley, e sacolo de pila el emperador don Alfonso, e después que fue christiano ovo grandes disputas con los sabios de los judíos, de lo qual escrevió un volumen de muy elegante e fermoso estilo, del qual fazen grant mención en las estorias Viçençio e frey Juan de Colupna, e frey Martín en la su Martiniana» ${ }^{15}$. Los tres autores citados pertenecen a la orden de los dominicos en el siglo XIII y la obra de los dos últimos, Giovanni Colonna y Martín el polonés, autor del Chronicon Pontificium et Imperatorum, conocido como Martiniana, depende estrechamente del Speculum historiale.

Otro eclesiástico del círculo de Alfonso de Cartagena, Diego Rodríguez de Almela (ca.1426-1489), vuelve a trazar un breve perfil de Pedro Alfonso en su Valerio de las estorias escolásticas de España:

Cuenta Vicencio estorial que un converso español, que se llamava maestre Pedro Alfon fue omne de grand sciencia, fizo un libro notable en declaración de nuestra sancta fe cathólica contra la perfidia de los phariseos judíos e fizo otras notables escripturas ${ }^{16}$.

Tanto Fernán Pérez de Guzmán como Diego Rodríguez de Almela incluyen a Pedro Alfonso en una larga nómina de varones ilustres, cuya vida es un ejemplo digno de imitar. En los dos casos las únicas adiciones a los datos aportados por Vicente de Beauvais vienen a destacar la raíz hispana del personaje, «natural de Castilla», según Pérez de Guzmán, y converso «español» para Almela. Ambos comparten una visión nacional de la historia que les lleva a incluir entre los sabios a todos aquellos nacidos en la Península, aunque pertenezcan a la época romana, árabe o visigoda.

Los Dialogi contra Iudaeos no sólo supusieron una auténtica novedad dentro de la apologética antijudía sino que, a través del título $\mathrm{V}$, contribuyeron a difundir por Occidente los dogmas principales del islam. La información aportada en este capítulo, en el que Pedro «intenta destruir la ley de los sarracenos y refutar la necedad de sus sentencias», se consideró imprescindible para los cruzados. No es extraño, pues, que en algunos manuscritos se copien los Dialogi, íntegros o sólo el título $\mathrm{V}$, junto a textos que tratan la historia de las Cruzadas. Así acabó llegando incluso a los lectores hispanos, tras una «peregrinación» que tuvo como destino final un precioso incunable zaragozano de 1498. El Viaje de la Tierra Santa, impreso por Pablo Hurus en 1498, es la traducción española de la Peregrinatio in Terram Sanctam del deán de Maguncia Bernhard von Breidenbach (ca.1440-1497). En esta obra, al tratar sobre las distintas sectas y errores, se incluye una versión abreviada del diálogo V, que se conoce así en la Pe-

15 Cancionero de Juan Fernández de Lxar, ed. cit, I, p. 334; Cancionero de Oñate-Castañeda, ed. Dorothy Sherman Severin, introducción Michel García, Madison, Hispanic Seminary of Medieval Texts, 1990, p. 91.

16 Diego Rodríguez de Almela, Valerio de las estorias escolasticas e de España, ed. Juan Torres Fontes, Murcia, Real Academia Alfonso X el Sabio, 1994, pp. 288-289. 
nínsula por vez primera en castellano, como ha mostrado Pedro Tena Tena ${ }^{17}$. El texto se esquematiza en cinco apartados, como se anuncia en el fol. 103r. Los cuatro primeros, que se centran en la vida de Mahoma, guardan una clara dependencia con el pasaje correspondiente de Vicente de Beauvais, retomado por otros cronistas dominicos. En el último, expone «los artículos del Corán» y su refutación, siguiendo para ello a «Pedro Alonso, que, siendo judío lo más criado entre los moros, fue convertido y hecho cristiano, acerca del año de Cristo Jesú mil CVI, contra quien un moro enbió los dichos XII artículos en esta manera. Y después luego viene la respuesta y aprobación de Pedro Alonso» (fol. 106v). Breidenbach ha tratado de restituir, sin lograrlo del todo, el esquema dialógico, haciendo que sea el propio Pedro Alfonso quien discuta con un moro, cambiando así su interlocutor original. A su vez, la adecuación al momento histórico, próximo a la caída de Constantinopla, le hace intercalar un inciso advirtiendo a los «turcos y los otros moros» de su segura condena (fol. 108v).

Ninguna de las referencias hasta ahora aducidas implica un conocimiento real de los escritos de Pedro Alfonso en Castilla. Para encontrarnos con sus lectores, o al menos con conocedores más o menos directos de su obra, hay que dirigirse hasta los polemistas, muchas veces también conversos, quienes recurren a los Dialogi para rebatir a sus antiguos correligionarios y defenderse de las críticas de los cristianos viejos. Sin embargo, muy raras veces usan el castellano para sus textos. De ahí el interés de los escritos de Alfonso de Valladolid (ca.12701346), cuya biografía guarda algún paralelismo con la de Pedro Alfonso ${ }^{18}$. Antiguo rabino y médico, Abner de Burgos cambió su nombre por el de Alfonso de Valladolid, cuando, tras su conversión, ocupó el cargo de sacristán en la colegiata de Valladolid. Es autor del Mostrador de justiçia, en el que para explicar su bautismo, defender los dogmas cristianos y rebatir los argumentos de los judíos, recurre a la disputa entre un «Rebelle» judío y un «Mostrador» cristiano. Entre las numerosas autoridades citadas, aparece también, en el capítulo correspondiente a la Santísima Trinidad, Pedro Alfonso, al que atribuye un Libro de las disputaciones, título que refleja las famosas «disputas» entre sabios judíos y cristianos. Pese al tiempo transcurrido todavía pueden aducirse los argumentos trinitarios de un posible rabino del XII, aunque sean rebatidos:

Mas Per Alfonso, el que escrivió en el Libro de las disputaciones que la perssona del Padre es dicho por la sustançia de Dios, e que la perssona del Fijo es dicho por la su sapiençia, e que la perssona del Spíritu Santo es dicho por la su voluntad, erró mucho, porque cada una de las tres perssonas de Dios es sustançia de Dios, non que la perssona del Padre solamient ${ }^{19}$.

La valoración de las obras de Pedro Alfonso se ha ido modificando con el transcurso del tiempo. Los Dialogi contra Iudaeos, por su contenido teológico, filosófico, científico, etc., le aseguraron la fama a su autor en los ambientes cultos, vinculando su nombre a los pocos datos que él mismo aportaba en su prólogo. Los relatos de la Disciplina fueron muy populares entre

17 Bernardo de Breidenbach, Viaje de la Tierra Santa, Madrid, Ministerio de Educación y Ciencia, Instituto Bibliográfico Hispano (Colección primeras ediciones, 2), 1974; Pedro Tena Tena, «Una versión incunable hispana de los Diálogos contra los judios de Pedro Alfonso», Sefarad, 57.1(1997), 179-194.

18 Carlos N. Sainz de la Maza, «De Pedro Alfonso a Abner-Alfonso: orto y cénit converso de la apologética antijudía medieval», Dicenda. Cuadernos de Filología Hispánica, 15 (1997), 271-288. Del mismo autor, Alfonso de Valladolid: edición y estudio del manuscrito «Vat. Lat. 6423» de la Biblioteca Apostólica Vaticana, Madrid, Universidad Complutense, 1990, y «El Toledot Yeshu castellano en el maestre Alfonso de Valladolid», en Actas del II Congreso Internacional de la Asociación Hispánica de Literatura Medieval (Segovia, del 5 al 9 de octubre de 1987), eds. J. M. Lucía Megías, P. Gracia Alonso y C. Martín Daza, Alcalá de Henares, Universidad de Alcalá, vol. II, 1992, pp. 797-814.

19 Alfonso de Valladolid (Abner aus Burgos), Mostrador de Justicia, ed. Walter Mettmann, Opladen, Westdeutscher Verlag, 1994, tomo I, p. 270. 
los predicadores, pero su consideración como obra literaria corresponde a una época moderna y va paralela al declive del tratado apologético. De ella se extraen algunas sentencias que se incorporarán a los numerosos florilegios medievales, auténticas compilaciones de sabiduría en pequeñas dosis. Un eco muy amortiguado de todo esto puede descubrirse en la literatura castellana de la Edad Media, donde, como hemos ido viendo, sus citas reflejan un conocimiento siempre indirecto, derivado de la recepción hispánica de las obras de autores franceses o italianos. Sólo los participantes en las numerosas polémicas religiosas que se sucedieron en la Península durante la Edad Media, o los conversos en sus tratados, recuerdan con mayor precisión los argumentos de Pedro Alfonso, auténtico precursor de estas controversias.

María Jesús Lacarra

Departamento de Literatura Española

Facultad de Filosofía y Letras

Pedro Cerbuna, 12 50009 Zaragoza 